\title{
Numerical Simulation of Hazardous Chemical Dispersion in the Industrial Area
}

\author{
M. W. Ko, C. B. Oh \\ Department of Safety Engineering \\ Pukyong National University \\ Republic of Korea
}

\begin{abstract}
The large eddy simulation (LES) was performed for the hydrogen fluoride (HF) leakage accident in Gumi fourth industrial complex, Korea. The fire dynamics simulator (FDS) was used for the simulation. A time-varying boundary condition for the wind direction was given to consider the realistic weather condition at the instant of the accident. It was found that the LES could predict the spatial distribution as well as temporal evolution of HF concentration effectively.
\end{abstract}

Keywords-large eddy simulation; fire dynamics simulator; hydrogen fluoride

\section{INTRODUCTION}

Various hazardous chemicals are used in the industrial processes throughout the world. There exists a potential possibility of accidents such as leakage, dispersion, fire and explosions arisen from the hazardous chemicals during the process. It is difficult to control the accidents related with the hazardous chemicals due to their complicated features. Recently, however, computational fluid dynamics (CFD) has been raised as a useful tool for the qualitative and quantitative risk assessment of the accidents.

In this study, a very precise CFD technique, large eddy simulation (LES), was performed to predict the dispersion characteristics of hydrogen fluoride (HF). The HF leakage accident, occurred in Gumi fourth industrial complex in Korea on September 2012, was selected as a computational object.

\section{NUMERICAL METHOD}

The fire dynamics simulator (FDS) v5.5.3 [1] was used in this simulation. The LES was adopted to predict the unsteady dispersion in large space from the HF leakage accident. The industrial area where HF leakage accident occurred was modelled three-dimensionally by the Pyrosim 2014 [2] using the on-site survey, map and satellite photograph.

\section{A. Governing Equation}

For the simulation of HF dispersion, the variable density should be considered. The Favre filtered LES governing equations for the simulation of HF dispersion were as follows:

Continuity conservation equation

$$
\frac{\partial \rho}{\partial t}+\nabla \cdot \rho \tilde{u}_{i}=0
$$

Momentum conservation equation

\author{
Y. S. Han, B. I. Choi, K. H. Do, M. B. Kim, T. H. Kim \\ Department of Energy Plant Safety \\ Korea Institute of Machinery and Materials \\ Republic of Korea
}

$$
\frac{\partial\left(\bar{\rho} \tilde{u}_{i}\right)}{\partial t}+\frac{\partial\left(\bar{\rho} \tilde{u}_{i} \tilde{u}_{j}\right)}{\partial x_{j}}=-\frac{\partial \bar{P}}{\partial x_{i}}+\left\{-\frac{2}{3} \bar{\mu} \frac{\partial\left(\tilde{u}_{k}\right)}{\partial x_{k}} \delta_{i j}+\bar{\mu}\left(\frac{\partial \tilde{u}_{i}}{\partial x_{j}}+\frac{\partial \tilde{u}_{j}}{\partial x_{i}}\right)\right\}+\bar{\rho} g_{i}+\frac{\partial \tau^{s g s}}{\partial x_{j}}
$$

Species conservation equation

$$
\frac{\partial\left(\bar{\rho} \tilde{Y}_{i}\right)}{\partial t}+\frac{\partial\left(\bar{\rho} \tilde{u}_{i} \tilde{Y}_{i}\right)}{\partial x_{j}}=\frac{\partial}{\partial x_{j}}\left\{\bar{\rho} \bar{D}_{i} \frac{\partial\left(\tilde{Y}_{i}\right)}{\partial x_{j}}\right\}
$$

where, FDS uses Smogorinsky subgrid model, and it expresses the following equation.

$$
\begin{gathered}
\tau^{\widetilde{u_{i} u_{j}}} \bar{\rho}\left(u_{i} u_{j}+\tilde{u}_{i} \tilde{u}_{j}\right) \\
=\frac{1}{3} \tau_{i j} \delta_{i j}-2 \bar{\rho}\left(C_{s}\right)^{2} \Delta^{2}|\tilde{S}| \tilde{S}_{i j}
\end{gathered}
$$

where, the constant, CS, is $0.2,|\tilde{S}|=\left(2 \tilde{S}_{i j} \tilde{S}_{i j}\right)^{2}$ and the strainrate tensor, $\tilde{S}_{i j}$, is expressed as the following equation.

$$
\tilde{S}_{i j}=\frac{1}{2}\left(\frac{\partial \tilde{u}_{i}}{\partial x_{j}}+\frac{\partial \tilde{u}_{j}}{\partial x_{i}}\right)_{(5)}
$$

where, referring to equation (1) to (5), $\bar{\rho}$ is the filtered density; $\tilde{u}_{i}$ is the Favre filtered velocity tensor; $\bar{P}$ is the filtered pressure; ${ }^{g} i$ is the acceleration of gravity of i direction; $\tau_{i j}$ is the shear stress tensor; $\tilde{Y}_{i}$ is the Favre filtered mass fraction of i species; $\bar{D}_{i}$ is the filtered turbulent diffusivity.

\section{B. Numerical Conditions}

The computational geometry for the simulation was determined as $L \times W \times H=1,300 \mathrm{~m} \times 1,300 \mathrm{~m} \times 255 \mathrm{~m}$. The uniform grid system was adopted, and the grid size was $2.5 \mathrm{~m}$ for each direction. To determine the HF ejection-duration time and flow rate, the result of previous study [3] was used. Thus, 
the ejection-duration time and flow rate of $\mathrm{HF}$ were determined as $1,800 \mathrm{~s}$ and $0.926 \mathrm{~kg} / \mathrm{s}$, respectively. As shown in table 1 , the weather condition during the HF leakage was obtained through the Korea Meteorological Administration. The OPEN boundary condition [4] for each surface was applied beside the boundaries where the wind condition was given. Additionally, the no-slip condition was applied for the bottom and building surfaces. The message-passing interface (MPI) parallel technique was adopted to reduce the computational time for the simulation of the large space. The computation was conducted with 35 cores (INTEL i7-3.5 $\mathrm{GHz}$ ), and $20 \mathrm{Hrs}$ was consumed for each case.

TABLE I. WIND BOUNDARY CONDITION

\begin{tabular}{|c|l|l|l|}
\hline $\begin{array}{c}\text { Time } \\
(\mathbf{s e c})\end{array}$ & \multicolumn{1}{|c|}{$\begin{array}{c}\text { Wind } \\
\text { direction }\end{array}$} & $\begin{array}{c}\text { Wind } \\
\text { velocity } \\
(\mathbf{m} / \mathbf{s})\end{array}$ & $\begin{array}{c}\text { Duration } \\
\text { time (sec) }\end{array}$ \\
\hline $0 \sim 1,000$ & West wind & 1.33 & 1,000 \\
\hline $\begin{array}{l}1,001 \sim \\
1,541\end{array}$ & West wind & 1.33 & 540 \\
\hline $\begin{array}{l}1,542 \sim \\
2,861\end{array}$ & $\begin{array}{l}\text { Northwest } \\
\text { wind }\end{array}$ & 1.15 & 1,319 \\
\hline $2,862 \sim$ & West wind & 1.20 & 1,638 \\
\hline 4,500 & & \multicolumn{3}{|c|}{ HF ejection instant: $1,001 \mathrm{~s}$} \\
\hline
\end{tabular}

\section{RESULTS}

\section{A. Dispersion Behaviour of Hydrogen Fluoride}

The HF dispersion behaviour around the accident region with the variation of the wind direction was shown in fig. 1 . The result represents the HF concentration at the height of 2.5 $\mathrm{m}$. The ejected HF moves to the eastern direction initially due to the west wind as shown in fig. 1 (a). At $1,868 \mathrm{~s}$, the HF concentration is distributed to the southeast direction, and the $\mathrm{HF}$ moves to the east direction again due to the west wind at $3,499 \mathrm{~s}$. Thus, it is seen from this result that realistic wind direction should be considered in the simulation for more accurate prediction of the HF distribution.

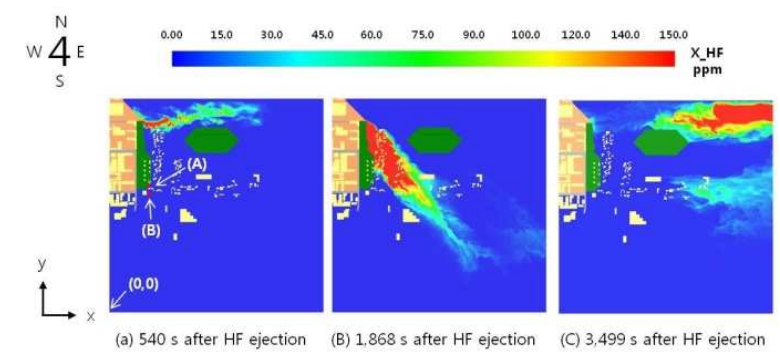

FIGURE I. TEMPORAL DISTRIBUTIONS OF HF CONCENTRATION FOR X-Y PLANE AT $Z=2.5 \mathrm{M}$

\section{B. Temporal Variation of the HF Concentration}

The HF can induce serious effects on the body due to its strong irritant property and toxicity. The chronic exposure to the HF can also cause large or small injuries in the eye or skin due to the stimulus [5]. To evaluate the danger of the hazardous chemicals, the Emergency Response Planning Guidelines (ERPG) guide-line was developed by American Industrial Hygiene Association (AIHA).
In fig. 2, the temporal evolution of HF concentrations at the selected locations was compared with the ERPG-1. The origin, $(0,0)$, locates at left lower corner in the fig. 1 . The HF concentration at $(250 \mathrm{~m}, 800 \mathrm{~m})$, the location of (A) in fig. 1 , is much higher than $(250 \mathrm{~m}, 750 \mathrm{~m})$, the location of (B) in fig. 1. This is because the location of (B) is nearer to the HF ejection point. The dotted line means the standard of ERPG-1 (2 ppm). The temporal HF concentrations at the selected two locations were compared with the ERPG-1. Since the HF concentration varies with time, fig. 2 shows the unsteady simulation is very useful to assess the risk of hazardous chemicals.

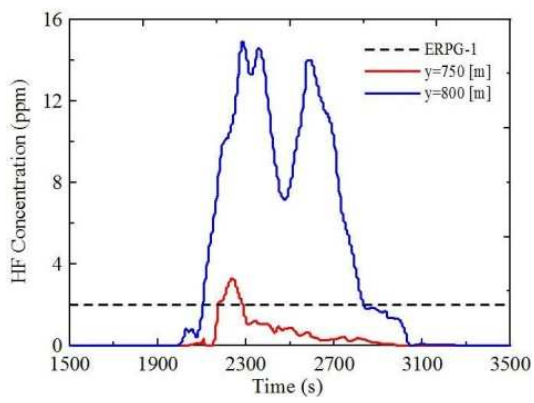

FIGURE II. COMPARISON OF ERPG-1 AND THE HF CONCENTRATION AT THE LOCATION OF (250 M, $750 \mathrm{M})$ AND (250 M, $800 \mathrm{M})$

\section{CONCLUSIONS}

The LES was performed for the HF leakage accident in Gumi, Korea. Contrary to the previous CFD studies, a timevarying boundary condition for the wind direction was given to consider the realistic weather condition at the instant of the accident. It was identified that the developed LES technique could predict the temporal evolution of HF concentration dispersion effectively.

\section{ACKNOWLEDGEMENT}

This work was supported by the principal research programs of the Korea Institute of Machinery and Materials (KIMM), Republic of Korea.

\section{REFERENCES}

[1] McGrattan, K., McDermott, R., Hostikka, S. \& Floyd, J., Fire Dynamics Simulator (Version 5) User's Guide, NIST Special Publication 1019-5, 2007.

[2] ThunderHead Engineering, Pyrosim User Manual, Manhattan, KS, 2014.

[3] Joo, H.Y., Lee, Y.S., Lim, O.J. \& Yoo, J.M., A study on the Improvement of Environmental Impact Assessment of Industrial Complexes Based on Risk Assessment of Chemical Leakage Accidents, Korea Environment Institute(KEI), 2013.

[4] McGrattan, K., Hostikka, S., Baum, H., Rehm, R., Mell, W. \& McDermott, R., Fire Dynamics Simulator (Version 5) Technical Reference Guide, NIST Special Publication 1018-5, 2007.

[5] Gu, S.G., Choi, I.J., Kim, W., Sun, O.N., Kim, S.B. \& Lee, Y.G., Study on the Distribution of Fluorides in Plants and the Estimation of Ambient Concentration of Hydrogen Fluoride in Gumi, Journal of the Environmental Health Science, 39(4), pp. 346-353, 2013. 